\title{
STUDY ON CHANGES IN SOME CHARACTERISTICS OF HUMAN CAPITAL IN THE REGION OF STARA ZAGORA
}

\author{
Iv. Angelova* \\ Faculty of Economics, Trakia University, Stara Zagora, Bulgaria
}

\begin{abstract}
In the recent years, human resources have increasingly been regarded as capital or "human capital". This trend reflects the ability of human resources to enhance their value and create a higher economic result, both for the separate economic subjects, and within the borders of territorial systems. The objective of the present study is to trace the changes in some quality characteristics of human capital in the region of Stara Zagora in the last five years. To realize this objective, we have applied the method of surveying people in working age by including questions related to improving qualification, motivation, innovativeness and talent of the respondents in the survey conducted in February-March of 2020. The survey results identify some problematic aspects of human capital and create the need for additional large-scale research on the separate regions of the country.
\end{abstract}

Key words: human capital, qualification, motivation, innovation, Stara Zagora region

\section{INTRODUCTION}

In recent years the attention towards human resources as capital, or human capital, has intensified, which reflects the ability to increase the value of human resource and create higher economic results both for the individual economic subjects, and within the borders of territorial systems. This process derives from the understanding that "capital as a category of economic theory is used to signify a certain economic resource which in time and due to its market functionality ascertains gain of value, income and affluence" (1). Other Bulgarian authors have also provided definitions for human resources and human capital (2-4), whereas the European Commission has been paying more attention to every side of human capital (5).

The objective of the present study is to trace the changes in some quality characteristics of human capital in the region of Stara Zagora in the past five years.

The tasks for realizing this objective are as follows:

\footnotetext{
*Correspondence to: Ivanka Angelova, Graduate student in the Master's Programme, Faculty of Economics, Trakia University, Stara Zagora, Bulgaria,e-mail:vanya_n_angelova@abv.bg
} \section{capital";}

Defining the concept of "human $>\quad$ Review of the information on human resources and human capital on the territory of Bulgaria and the region of Stara Zagora;

$>\quad$ Conducting a survey among people in working age

The subjects of this study are people in working age from the region of Stara Zagora. The object of the study is to identify some problematic aspects in the characteristics of human capital in the period of 2016-2020.

During the study we have applied the method of surveying people in working age by including questions related to improving their qualification, motivation, innovativeness and talent. The survey took place in FebruaryMarch 2020.

\section{Essence and meaning of human capital}

At the basis of human capital are people who work or are qualified to work in a given territorial unit or an economic subject. When the quantity aspects of human resources are observed, it is usually the indicators monitored by the National Statistical Institute or the Territorial Statistical Offices that are being analyzed. 
Human capital is the ability to increase the value of the human resources within the economic or territorial unit in order to stimulate the growth of the capacity for physical, mental or administrative labour. The evaluation of human capital is performed at two levels - micro and macro-level.

\section{Micro-level-physical and economic subject}

$>$ Improved qualification by accumulation of knowledge, experience, acquired skills

> Improved: health state, motivation, adaptability, innovativeness, entrepreneurial readiness, capacity for decision-making and tackling problems, development of talent

Macro-level - social system

$$
\begin{array}{ll}
> & \text { Migration flow } \\
> & \text { Inter-generational relations } \\
> & \text { Creativity }
\end{array}
$$

The characteristics of human capital include knowledge, skills, experience and social qualities which contribute to the ability of an individual to perform work in a way that leads to creating goods of a higher economic value. Both employers and staff in an organization are responsible for investing in the development of human capital. The theory of human capital includes determining the real value of an investment in human capital and is closely related to the characteristics of human resources. Much more decisive is the role of quality characteristics of human resources because they are at the base of adding value to material goods.

In 2018 the World Bank published a report calculating the index of human capital. Several components have been included in it, among which child mortality, access to education and the quality of the educational system and healthcare.

The role of education and healthcare is emphasized more and more as key factors which may lead to an improved human capital, and also to contribute to economic growth.

Bulgaria is at $44^{\text {th }}$ place out of 157 countries. Our country has a better ranking than states with similar incomes, yet much worse than other Central and Eastern European countries. Bulgaria lags behind the average indicators for the European Union as a whole. States from Western Europe, such as Germany, Austria, the UK and Denmark are among the top 20, whereas Serbia, Poland and Hungary are respectively at $28^{\text {th }}, 31^{\text {st }}$ and $39^{\text {th }}$ place.

\section{RESULTS}

Human capital in Bulgaria and the region of Stara Zagora

Table 1. Index for human capital, 2018

\begin{tabular}{|l|l|l|}
\hline Position & Ranking & Index \\
\hline 1 & Singapore & 0.88 \\
\hline 2 & South Korea & 0.84 \\
\hline 3 & Japan & 0.84 \\
\hline 4 & Hong Kong & 0.82 \\
\hline 5 & Finland & 0.81 \\
\hline 6 & Ireland & 0.81 \\
\hline 7 & Australia & 0.80 \\
\hline 8 & Sweden & 0.80 \\
\hline 9 & The Netherlands & 0.80 \\
\hline 10 & Canada & 0.80 \\
\hline$\ldots$ & $\ldots$ & $\ldots$ \\
\hline 42 & Greece & 0.68 \\
\hline 43 & Republic of Seychelles & 0.68 \\
\hline 44 & Bulgaria & 0.68 \\
\hline 45 & Chile & 0.67 \\
\hline 46 & China & 0.67 \\
\hline 47 & Bahrain & 0.67 \\
\hline$\ldots$ & $\ldots$ & $\ldots$ \\
\hline 153 & Liberia & 0.32 \\
\hline 154 & Mali & 0.32 \\
\hline 155 & Niger & 0.32 \\
\hline 156 & South Sudan & 0.30 \\
\hline 157 & Chad & 0.29 \\
\hline
\end{tabular}

Source: World Bank 
In the last 5-6 years the formed structures and on-going processes in the demographic development of the region of Stara Zagora have outlined the relatively stable development of the population and the human resources in the region.

The aging process is more prevalent in rural populations. Fertile contingents and their structure are within the normal reproduction rates.

In 8 out of 11 municipalities the share of the population under working age is higher than the average for the country.
In all municipalities of the region (without the municipality of Stara Zagora) the share of the population in working age is below the average for the country.

The trends versus 2014 are favorable: the share of the youngest age group has increased (with the exception of Opan and Radnevo). This is parallel to the growth of the share of the population in working age (except for Stara Zagora and Kazanlak).

The municipality of Nikolaevo ranks first in Bulgaria for birth coefficient (18\%) and for rate of natural increase $(2.0 \%)$.

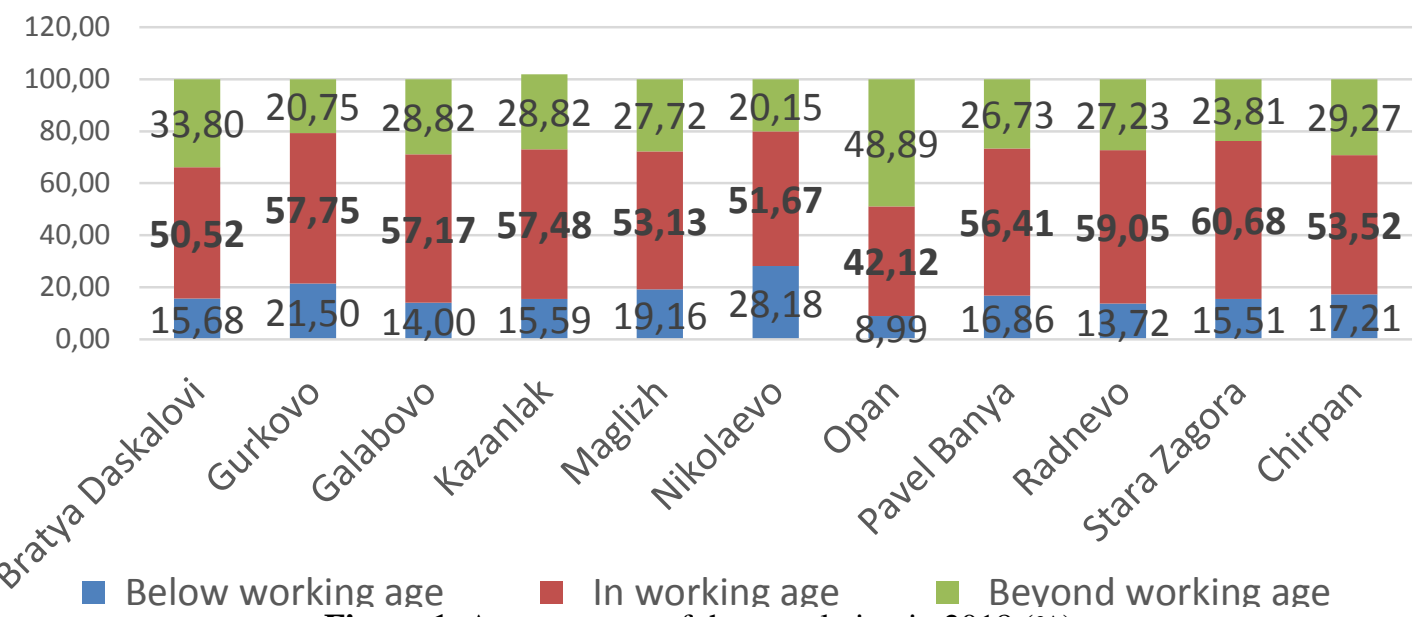

Figure 1. Age structure of the population in 2018 (\%)

\begin{tabular}{|l|l|l|l|}
\hline & Below working age & In working age & Beyond working age \\
\hline Stara Zagora region & 15,87 & 58,35 & 25,78 \\
\hline Bulgaria & 15,24 & 60,01 & 24,74 \\
\hline
\end{tabular}

The educational level of the population constantly increases with $60 \%$ of the persons at the age of 27 and above holding a high educational level (higher, specialist and secondary education), which is due primarily to the population in the town of Stara Zagora.
Most people with higher education are located in the center of the municipality, while in villages the biggest share is of the population with elementary education.

\section{SURVEY RESULTS}

\section{How did you improve your qualification in the last 5 years?}

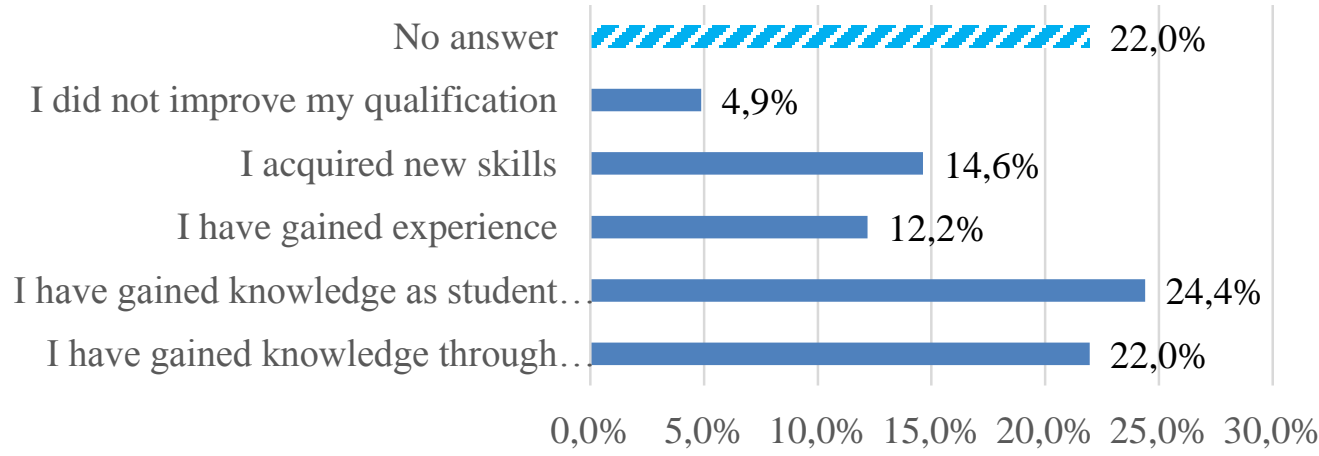

Figure 2. How did you improve your qualification in the last 5 years? 
Are you more motivated to work now versus 5 years ago?

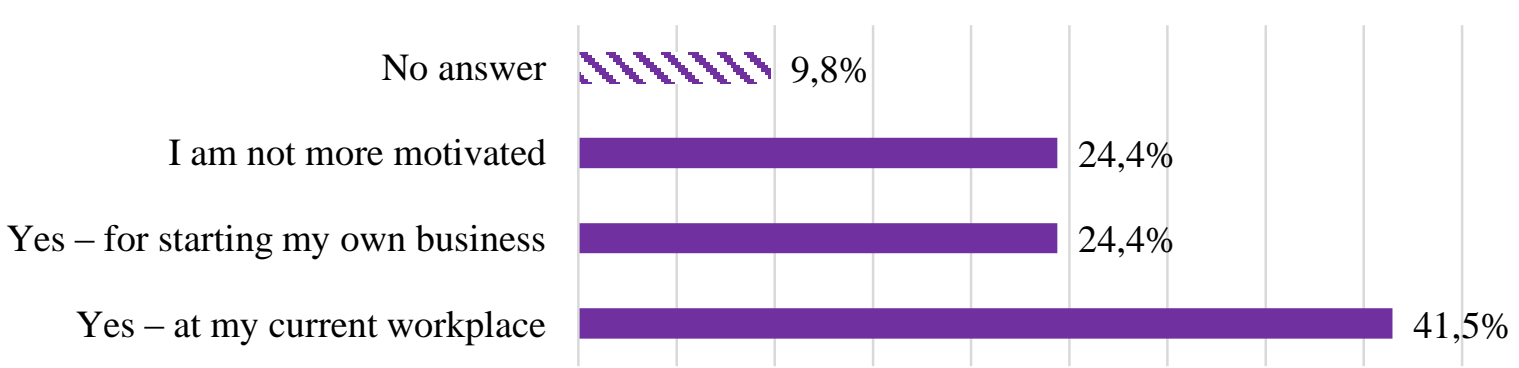

$0,0 \% 5,0 \% 10,0 \% 15,0 \% 20,0 \% 25,0 \% 30,0 \% 35,0 \% 40,0 \% 45,0 \%$

Figure 3. Are you more motivated to work now versus 5 years ago?

Motivation is an important aspect of the characteristic of human capital. The biggest share belongs to those who have answered positively from their current workplace. Those who feel motivated to start their own business are $24.4 \%$, the same as the share is the same as of those who do not have a better motivation for work.

\section{Are you more innovative now versus 5 years ago?}

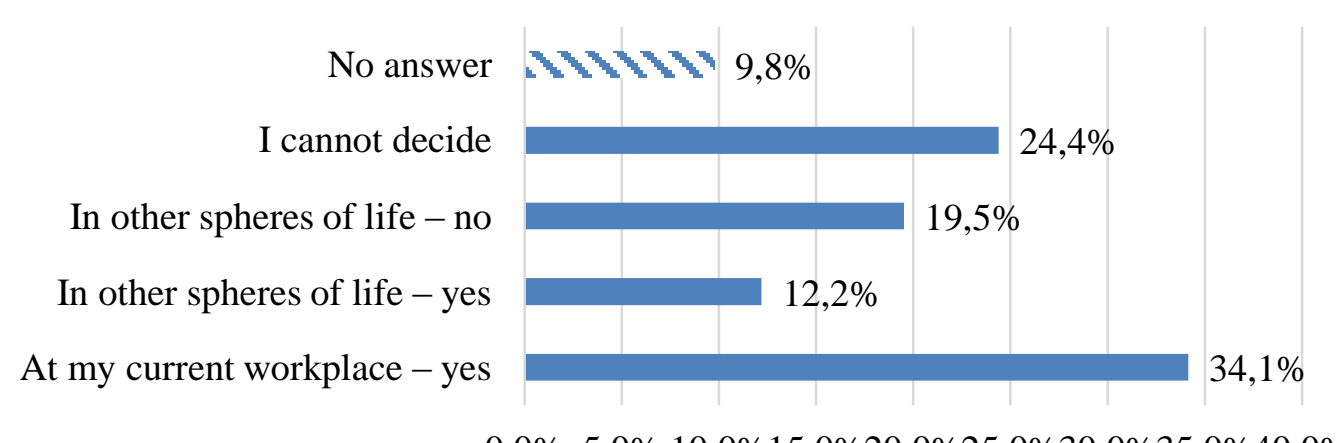

Figure 4. Are you more innovative now versus 5 years ago?

The self-evaluation for innovativeness has been problematic for the respondents - a third has not given such an evaluation because they could not decide or they have ignored the question. Twice as more are those who feel innovative at their current workplace compared to those with better innovativeness in other spheres of life.

\section{Have you developed a personal talent in the last 5 years?}

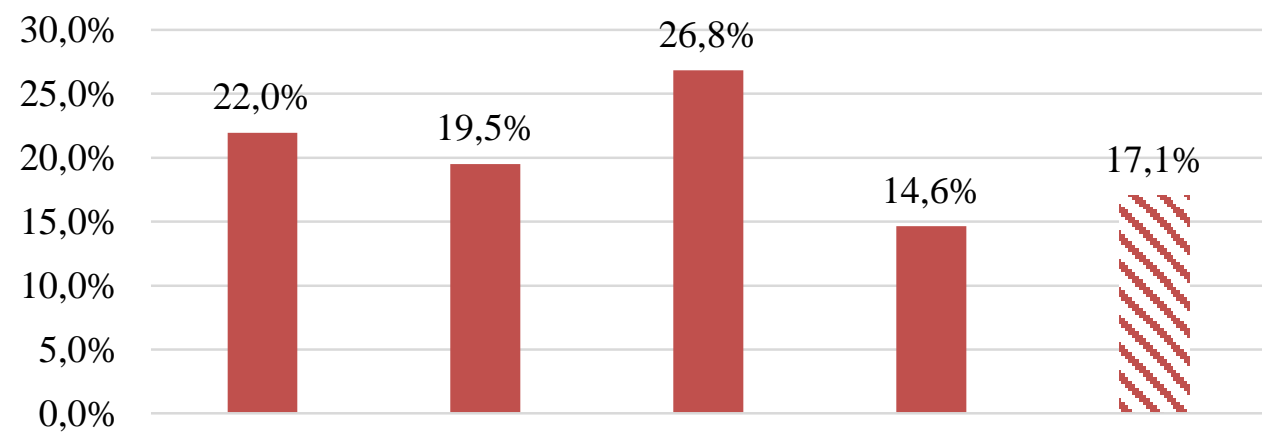

Yes, because Yes, because I I have no I have not had No answer it is related to have free time special talent my work the opportunity to develop a talent

Figure 5. Have you developed a personal talent in the last 5 years? 
Almost $27 \%$ of the respondents have not recognized any personal talent, which together with those who did not give an answer (17.1\%) form a little less than half of the participants in the survey. Some of the people (14.6\%) think that they have not been given the opportunity. A third, however, confirm that they have developed a personal talent - almost equal to those who have indicated work as the reason for selfimprovement and those who had free time to develop themselves.

In order to evaluate human capital at a macrolevel it is important to check the attitudes toward retaining it within the borders of the respective territorial unit of locality.

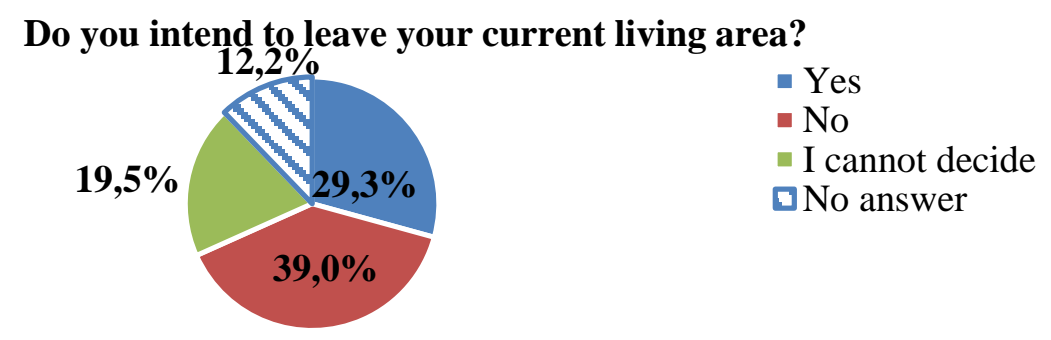

Figure 6. Do you intend to leave your current living area?

Unarguably, the largest percent of people do not intend to leave their living area. However, the share of those who are considering the option is not that little either $-29.3 \%$.

\section{Have intergenerational relations improved in the last 5 years?

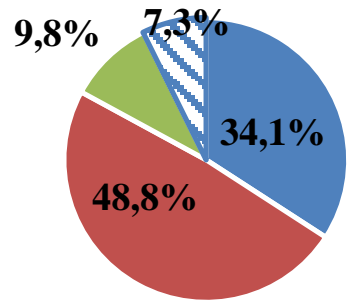 \\ - Yes \\ - No \\ - I cannot decide \\ $\square$ No answer}

Figure 7. Have intergenerational relationships improved in the last 5 years?

Intergenerational relationships are very difficult to evaluate by the respondents $-34.1 \%$ have not answered, and $9.8 \%$ could not formulate an opinion. Most respondents indicate that there is no improvement in intergenerational relations which definitely delays the development of human capital at a macro-level.
The difficult evaluation of human capital at a macro-level is confirmed by the structure of the responses to the question "Has public (social) life improved in your living area in the last 5 years?" - almost half of the participants either did not give an answer, or could not offer any judgment. However, $51.2 \%$ think that there is an improvement in the social life of people.

Has public (social) life improved in your living area in the last 5 years?

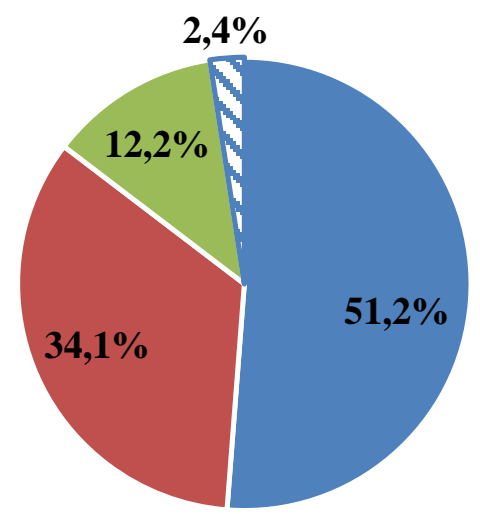

- Yes $\quad$ No $\quad$ I cannot decide $\quad$ No answer

Figure 8. Has public (social) life improved in your living area in the last 5 years? 
The survey results have identified some problematic aspects of human capital and created a need for additional larger scale research on the separate regions of the country.

\section{CONCLUSIONS}

There are tendencies for delaying the unfavorable demographic trends and improvement of the age and educational structure of the region of Stara Zagora.

The information which the survey provides about the subjective assessment of some quality characteristics of human capital among people in working age shows that:

A. Human resources require better awareness of the possibilities to improve qualification and the ways to evaluate it.

B. There is unused potential for improvement of qualification through life-long learning.

C. It is necessary to find ways to motivate human resources to work, including motivational forms at the workplace.

D. Innovativeness is not developed enough both at the workplace, and in the other spheres of life.

E. There is a need to support the search for talent in people working in a specific sphere.
ANGELOVA IV.

F. From the perspective of community capacity - there is still instability related to: inclination for issuing migration, insufficient good generational relations, weak progress in improving social life in separate localities.

\section{REFERENCES}

1. Kazakov, At. Human Capital: Conceptual Frame and Functional Methodology (in Bulgarian),

https://www.unwe.bg/uploads/ResearchPap ers/Research\%20Papers_vol1_2010_No1_

A\%20Kazakov.pdf

2. Vedar, Ol 2014., Management of Human resources, AP "St. Kliment Ohridski", ISBN: 978-954-07-3809-3

3. Dulevski, L. 2009, Methodological challenges for the assessment of human capital and return on investment in it, UNWE, Scientific Papers, Volume 2/2009, AP "Economy"

4. Nedelcheva, N., 2017, Labor Economics, AP "University of Ruse", ISBN: 978-954712-727-2

5. Sienkiewicz, Ł., 2018, Human Resource Management: How To Attract, Retain And Develop Talent, European Commission, European Union, 2018, ISBN 978-92-7993924-2 